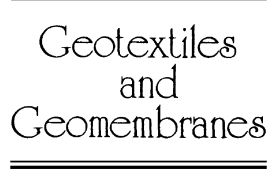

\title{
A nonlinear homogenized model applicable to reinforced soil analysis
}

\author{
Tien-Chien Chen ${ }^{\mathrm{a}}$, Rong-Her Chen ${ }^{\mathrm{b}}$, San-Shyan Lin ${ }^{\mathrm{c}, *}$
}

\author{
${ }^{a}$ Sino-Geotechnology Co., Inc., 6F-2, \# 50, Nanking E. Rd., Sec. 4, Taipei, Taiwan \\ ${ }^{\mathrm{b}}$ Department of Civil Engineering, National Taiwan University, Taipei, 10617, Taiwan \\ ${ }^{\mathrm{c}}$ Department of Harbor and River Engineering, Taiwan Ocean University, Keelung, 20224, Taiwan
}

Received 12 March 1999; received in revised form 11 August 1999; accepted 23 October 1999

\begin{abstract}
A numerical procedure for the analysis of reinforced soil structures is proposed, which uses the homogenized transversely isotropic concept. The nonlinear behavior of the reinforced soil and proper boundary conditions are considered in the model. The proposed model is programmed using the commercial computer code FLAC for numerical analysis. Two numerical examples of reinforced soil wall analysis are presented to study the validity and applicability of the proposed method. The results obtained are compared with experimental and analytical work obtained by other investigators. (C) 2000 Elsevier Science Ltd. All rights reserved.
\end{abstract}

Keywords: Homogenized model; Reinforced soil; Nonlinear analysis

\section{Introduction}

The discrete and the equivalent homogeneous methods are usually used to model the behaviors of a reinforced soil (Chen, 1998; Lee and Holtz, 1998; Chen and Chen, 1997; Sampaco, 1996; Wu, 1991; Moroto and Hasegawa, 1990; Gerrard, 1982; Romstad et al., 1976; and Harrison and Gerrard, 1972). In the first method, different mathematical models are often separately used to simulate the soil, the reinforcement and the soil/reinforcement interface behaviors (Sampaco, 1996; and Romstad et al., 1976). Although the interaction behaviors of each component may be obtained in the

\footnotetext{
* Corresponding author. Tel.: 886-2-24622192/Ext. 6139; Fax: 886-2-24623679.

E-mail address: sslin@ntou66.ntou.edu.tw (S.S. Lin).
} 


$\begin{array}{ll}\text { Nomenclature } & \\ A^{\mathrm{c}}, A^{\mathrm{r}}, A^{\mathrm{s}} & \begin{array}{l}\text { Cross-sectional area of the reinforced composite, reinforcement and } \\ \text { soil, respectively }\end{array} \\ E_{\mathrm{h}}^{\mathrm{c}}, E_{\mathrm{v}}^{\mathrm{c}}, E_{\mathrm{z}}^{\mathrm{c}} & \begin{array}{l}\text { Tangent moduli of the reinforced soil in the horizontal, vertical and } \\ \text { transversal directions, respectively }\end{array} \\ E^{\mathrm{r}}, E^{\mathrm{s}} & \begin{array}{l}\text { Tangent moduli of the reinforcement and soil, respectively } \\ E^{\mathrm{si}}\end{array} \\ G_{\mathrm{hz}}^{\mathrm{c}}, G_{\mathrm{hv}}^{\mathrm{c}} & \begin{array}{l}\text { Initial tangent modulus of the soil } \\ \text { Shear moduli of the reinforced soil in the hz and hv or zv plane, } \\ \text { respectively }\end{array} \\ \delta \varepsilon_{\mathrm{h}}^{\mathrm{c}}, \delta \varepsilon_{\mathrm{v}}^{\mathrm{c}}, \delta \varepsilon_{\mathrm{z}}^{\mathrm{c}} & \begin{array}{l}\text { Strain increment of the reinforced composite in the horizontal, } \\ \text { vertical and transversal directions, respectively }\end{array} \\ \delta \varepsilon_{\mathrm{h}}^{\mathrm{r}}, \delta \varepsilon_{\mathrm{v}}^{\mathrm{r}}, \delta \varepsilon_{\mathrm{z}}^{\mathrm{r}} & \begin{array}{l}\text { Strain increment of the reinforcement in the horizontal, vertical and } \\ \text { transversal directions, respectively }\end{array} \\ \delta \varepsilon_{\mathrm{h}}^{\mathrm{s}}, \delta \varepsilon_{\mathrm{v}}^{\mathrm{s}}, \delta \varepsilon_{\mathrm{z}}^{\mathrm{s}} & \begin{array}{l}\text { Strain increment of the soil in the horizontal, vertical and transver- } \\ \text { sal directions, respectively }\end{array} \\ \delta \sigma_{\mathrm{h}}^{\mathrm{c}}, \delta \sigma_{\mathrm{v}}^{\mathrm{c}}, \delta \sigma_{\mathrm{z}}^{\mathrm{c}} & \begin{array}{l}\text { Stress increment of the reinforced soil in the horizontal, vertical and } \\ \text { transversal directions, respectively }\end{array} \\ \delta \sigma_{\mathrm{h}}^{\mathrm{r}}, \delta \sigma_{\mathrm{v}}^{\mathrm{r}}, \delta \sigma_{\mathrm{z}}^{\mathrm{r}} & \begin{array}{l}\text { Stress increment of the reinforcement in the horizontal, vertical and } \\ \text { transversal directions, respectively }\end{array} \\ \delta \sigma_{\mathrm{h}}^{\mathrm{s}}, \delta \sigma_{\mathrm{v}}^{\mathrm{s}}, \delta \sigma_{\mathrm{z}}^{\mathrm{s}} & \begin{array}{l}\text { Stress increment of the soil in the horizontal, vertical and transver- } \\ \text { sal directions, respectively }\end{array} \\ v_{\mathrm{hv}}^{\mathrm{c}}, v_{\mathrm{zv}}^{\mathrm{c}} & \begin{array}{l}\text { Poisson's ratio of the reinforced soil that characterizes the vertical } \\ \text { strain due to the horizontal and transversal direction stresses, } \\ v_{\mathrm{hz}}^{\mathrm{c}}, v_{\mathrm{vz}}^{\mathrm{c}}\end{array} \\ v_{\mathrm{m}}^{\mathrm{r}}, v^{\mathrm{s}} & \begin{array}{l}\text { respectively } \\ \text { Poisson's ratio of the reinforced soil that characterizes the transver- } \\ \text { sal strain due to the horizontal and vertical direction stress, respec- } \\ \text { tively } \\ \text { Poisson's ratio of the reinforced soil that characterizes the horizon- } \\ \text { tal strain due to the vertical and transversal direction stresses, } \\ \text { respectively }\end{array} \\ \begin{array}{l}\text { Poisson's ratio of the reinforcement and soil, respectively } \\ \text { Mean stress }\end{array}\end{array}$

analysis, the interface model cannot be easily characterized. In addition, the reinforcement is horizontally superimposed on the soil matrix, which enhances the stiffness of the reinforced medium under tension (neglecting possibly under compression or kinking here) in the horizontal direction but not the vertical stiffness or the shear modulus. Macroscopically, the equivalent homogeneous method considers an anisotropic reinforced soil as a homogeneous medium, using the weighted strength or weighted stiffness concept (Michalowski and Zhao, 1995; Moroto et al., 1990; Anthoine, 1989; Buhan et al., 1989; Gerrard, 1982; and Harrison and Gerrard, 1972). Either extensible or nonextensible reinforcement has been treated in the analysis. 
Harrison and Gerrard (1972) used the equivalent homogenizing material concept to define the material properties of a system of alternating isotropic layers consisting of soft earth and a set of parallel and equally spaced reinforcing sheets or meshes. Only linear elastic material behavior was considered in the model. Furthermore, Gerrard (1982) extended the equivalent material concept to take into account two or three orthorhombic layers of reinforcement. However, the semi-infinite condition for the considered reinforced structure was assumed in the model, which does not satisfy some reinforced soil structures, such as reinforced soil walls. Another approach by Romstad et al. (1976) used the composite stress concept to define the properties of an orthorhombic material. The soil nonlinearity properties were considered due to confining pressures only. Some recent researches on homogenization of plastic properties of reinforced soils were studied by Michalowski and Zhao (1995), Anthoine (1989), and Buhan et al. (1989).

Since the reinforcement is often horizontally embedded in layers in the soil, an orthotropic or a transversely isotropic model is commonly used in the homogeneous method. In this paper, a more general form of the plane strain homogenizing reinforced soil model using a transversely isotropic concept is proposed. Both linear and nonlinear reinforced soil behaviors are included in the model. The validity of the proposed model is shown through comparison with existing experimental data.

\section{Homogenized transversely isotropic reinforced soil model}

A soil/reinforcement composite material, with the transversely isotropic property, is treated as an equivalent homogeneous medium. Five parameters, which include the tangent moduli of the reinforced soil in the horizontal and vertical directions, respectively, the Poisson's ratios in the anti-plane and in-plane directions, respectively, and the shear modulus, are required to describe the behavior of the medium. In order to simplify the considered system, two assumptions are made: (a) both the reinforcement and the soil are assumed to be isotropic materials; (b) the perfect bond condition is assumed at the interface between the soil and the reinforcement.

\subsection{Elastic modulus in the horizontal direction}

As mentioned earlier, the proposed homogenized model includes five parameters, which can be determined from five equilibrium or compatibility relations.

The schematic diagram of a reinforced soil system is shown in Fig. 1. In the figure, $A^{\mathrm{c}}$ is the cross-sectional area of the reinforced composite; $S^{\mathrm{c}}$ the thickness of the reinforced somposite; $A^{\mathrm{s}}$ the cross-sectional area of the soil; $S^{\mathrm{s}}$ the thickness of the soil; $A^{\mathrm{r}}$ the cross-sectional area of the embedded reinforcement; $S^{\mathrm{r}}$ the thickness of the reinforcement.

Similar to other homogenization concepts (Michalowski and Zhao, 1995; Moroto and Hasegawa, 1990; and Buhan et al., 1989), the reinforcing ratio, $\eta$, is defined here as 


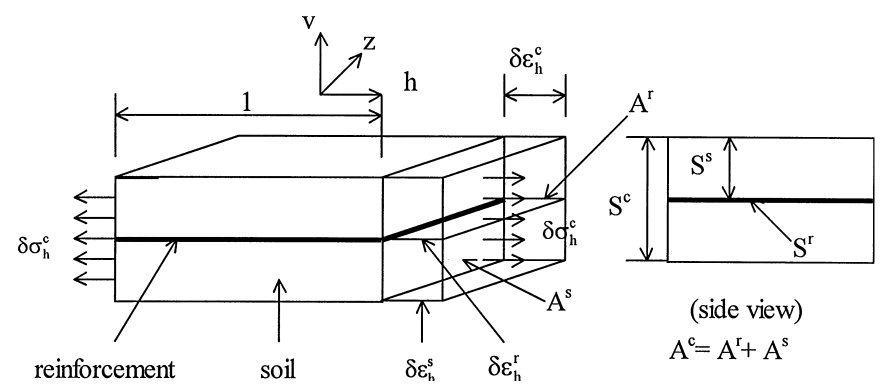

Fig. 1. Free body diagram of the soil-reinforcement system.

the ratio of the reinforcement volume, $V^{\mathrm{r}}$, to the soil volume, $V^{\mathrm{s}}$, and is expressed as

$$
\eta=\frac{V^{\mathrm{r}}}{V^{\mathrm{s}}}=\frac{A^{\mathrm{r}}}{A^{\mathrm{s}}}=\frac{S^{\mathrm{r}}}{S^{\mathrm{s}}}
$$

Based on static equilibrium, the total stress on the element is the sum of the stresses acting on the fiber and on the matrix, as shown in Fig. 1. Hence, the stress distribution along the cross-sectional area of the reinforced soil element is

$$
\delta \sigma_{\mathrm{h}}^{\mathrm{c}} A^{\mathrm{c}}=\delta \sigma_{\mathrm{h}}^{\mathrm{r}} A^{\mathrm{r}}+\delta \sigma_{\mathrm{h}}^{\mathrm{s}} A^{\mathrm{s}},
$$

where $\delta \sigma_{\mathrm{h}}^{\mathrm{c}}, \delta \sigma_{\mathrm{h}}^{\mathrm{r}}$ and $\delta \sigma_{\mathrm{h}}^{\mathrm{s}}$ are the horizontal stress increments of the reinforced composite, reinforcement, and soil, respectively.

Dividing (2) by $A^{\text {s }}$ and then substituting (1) into (2), we can express the stress distribution in the cross section as

$$
\delta \sigma_{\mathrm{h}}^{\mathrm{c}}=\frac{\eta}{1+\eta} \delta \sigma_{\mathrm{h}}^{\mathrm{r}}+\frac{1}{1+\eta} \delta \sigma_{\mathrm{h}}^{\mathrm{s}} .
$$

The incremental strain of the reinforced composite in the horizontal direction, $\delta \varepsilon_{\mathrm{h}}^{\mathrm{c}}$, can be represented in incremental form as (Chen et al., 1999)

$$
\delta \varepsilon_{\mathrm{h}}^{\mathrm{c}}=\frac{\delta \sigma_{\mathrm{h}}^{\mathrm{c}}}{E_{\mathrm{h}}^{\mathrm{c}}}-\frac{\nu_{\mathrm{vh}}^{\mathrm{c}}}{E_{\mathrm{v}}^{\mathrm{c}}} \delta \sigma_{\mathrm{v}}^{\mathrm{c}}-\frac{v_{\mathrm{zh}}^{\mathrm{c}}}{E_{\mathrm{z}}^{\mathrm{c}}} \delta \sigma_{\mathrm{z}}^{\mathrm{c}}
$$

where $\delta \sigma_{\mathrm{v}}^{\mathrm{c}}$ and $\delta \sigma_{\mathrm{z}}^{\mathrm{c}}$ are the stress increment of the reinforced composite in the vertical and transversal directions, respectively. The superscript $c$ represents the reinforced composite. $v_{\mathrm{vh}}^{\mathrm{c}}$ and $v_{\mathrm{zh}}^{\mathrm{c}}$ the Poisson's ratio of the reinforced composite that characterizes the horizontal strain due to the vertical and transversal direction stresses, respectively. $E_{\mathrm{h}}^{\mathrm{c}}, E_{\mathrm{v}}^{\mathrm{c}}$ and $E_{\mathrm{z}}^{\mathrm{c}}$ the tangent moduli of the reinforced composite in the horizontal, vertical, and transversal directions, respectively.

Similarly, the incremental strain in the horizontal direction of the reinforcement and the soil, respectively, can be written as

$$
\delta \varepsilon_{\mathrm{h}}^{\mathrm{r}}=\frac{\delta \sigma_{\mathrm{h}}^{\mathrm{r}}}{E^{\mathrm{r}}}-\frac{v^{\mathrm{r}}}{E^{\mathrm{r}}} \delta \sigma_{\mathrm{v}}^{\mathrm{r}}-\frac{v^{\mathrm{r}}}{E^{\mathrm{r}}} \delta \sigma_{\mathrm{z}}^{\mathrm{r}}
$$




$$
\delta \varepsilon_{\mathrm{h}}^{\mathrm{s}}=\frac{\delta \sigma_{\mathrm{h}}^{\mathrm{s}}}{E^{\mathrm{s}}}-\frac{\nu^{\mathrm{s}}}{E^{\mathrm{s}}} \delta \sigma_{\mathrm{v}}^{\mathrm{s}}-\frac{\nu^{\mathrm{s}}}{E^{\mathrm{s}}} \delta \sigma_{\mathrm{z}}^{\mathrm{s}},
$$

where $\delta \varepsilon_{\mathrm{h}}^{\mathrm{r}}$ and $\delta \varepsilon_{\mathrm{h}}^{\mathrm{s}}$ are the horizontal strain increment of the reinforcement and the soil, respectively, and $v^{\mathrm{r}}$ and $v^{\mathrm{s}}$ the Poisson's ratio of the reinforcement and the soil, respectively. The other symbols are explained in the nomenclature.

In addition, based on the earlier assumption that the reinforced soil is a transversely isotropic material, we find that

$$
E_{\mathrm{h}}^{\mathrm{c}}=E_{\mathrm{z}}^{\mathrm{c}} ; \quad v_{\mathrm{hz}}^{\mathrm{c}}=v_{\mathrm{zh}}^{\mathrm{c}} .
$$

The incremental strains, $\delta \varepsilon_{\mathrm{h}}^{\mathrm{c}}$, become

$$
\delta \varepsilon_{\mathrm{h}}^{\mathrm{c}}=\frac{\delta \sigma_{\mathrm{h}}^{\mathrm{c}}}{E_{\mathrm{h}}^{\mathrm{c}}}-\frac{\nu_{\mathrm{vh}}^{\mathrm{c}}}{E_{\mathrm{v}}^{\mathrm{c}}} \delta \sigma_{\mathrm{v}}^{\mathrm{c}}-\frac{v_{\mathrm{hz}}^{\mathrm{c}}}{E_{\mathrm{h}}^{\mathrm{c}}} \delta \sigma_{\mathrm{z}}^{\mathrm{c}}
$$

Similarly, $\delta \varepsilon_{\mathrm{v}}^{\mathrm{c}}$ and $\delta \varepsilon_{\mathrm{z}}^{\mathrm{c}}$ can be obtained using similar procedures as

$$
\begin{aligned}
& \delta \varepsilon_{\mathrm{v}}^{\mathrm{c}}=-\frac{\nu_{\mathrm{hv}}^{\mathrm{c}}}{E_{\mathrm{h}}^{\mathrm{c}}} \delta \sigma_{\mathrm{h}}^{\mathrm{c}}+\frac{\delta \sigma_{\mathrm{v}}^{\mathrm{c}}}{E_{\mathrm{v}}^{\mathrm{c}}}-\frac{\nu_{\mathrm{hv}}^{\mathrm{c}}}{E_{\mathrm{h}}^{\mathrm{c}}} \delta \sigma_{\mathrm{z}}^{\mathrm{c}}, \\
& \delta \varepsilon_{\mathrm{z}}^{\mathrm{c}}=-\frac{\nu_{\mathrm{hz}}^{\mathrm{c}}}{E_{\mathrm{h}}^{\mathrm{c}}} \delta \sigma_{\mathrm{h}}^{\mathrm{c}}-\frac{\nu_{\mathrm{vh}}^{\mathrm{c}}}{E_{\mathrm{v}}^{\mathrm{c}}} \delta \sigma_{\mathrm{v}}^{\mathrm{c}}+\frac{\delta \sigma_{\mathrm{z}}^{\mathrm{c}}}{E_{\mathrm{h}}^{\mathrm{c}}} .
\end{aligned}
$$

Incorporating a longitudinal incremental normal stress, $\delta \sigma_{\mathrm{h}}^{\mathrm{c}}$, as shown in Fig. 1, and also considering the plane strain condition, Eq. (10) can be written as

$$
\delta \sigma_{\mathrm{z}}^{\mathrm{c}}=v_{\mathrm{hz}}^{\mathrm{c}} \delta \sigma_{\mathrm{h}}^{\mathrm{c}} .
$$

Similarly, the incremental stress-strain relationships for the reinforcement and soil, respectively, are

$$
\delta \sigma_{\mathrm{z}}^{\mathrm{r}}=v^{\mathrm{r}} \delta \sigma_{\mathrm{h}}^{\mathrm{r}},
$$

and

$$
\delta \sigma_{\mathrm{z}}^{\mathrm{s}}=v^{\mathrm{s}} \delta \sigma_{\mathrm{h}}^{\mathrm{s}} .
$$

In addition, assuming that the average strains in the composite, reinforcement, and soil, respectively, along the longitudinal direction are equal, we have

$$
\delta \varepsilon_{\mathrm{h}}^{\mathrm{c}}=\delta \varepsilon_{\mathrm{h}}^{\mathrm{r}}=\delta \varepsilon_{\mathrm{h}}^{\mathrm{s}} .
$$

Hence, we can combine Eqs. (5), (6), (8) and (14) to get

$$
\delta \sigma_{\mathrm{h}}^{\mathrm{s}}=\frac{E^{\mathrm{s}} \delta \sigma_{\mathrm{h}}^{\mathrm{c}}\left(1-v_{\mathrm{h}}^{\mathrm{c}^{2}}\right)}{E_{\mathrm{h}}^{\mathrm{c}}\left(1-v^{\mathrm{s}^{\mathrm{z}}}\right)}
$$

and

$$
\delta \sigma_{\mathrm{h}}^{\mathrm{r}}=\frac{E^{\mathrm{r}} \delta \sigma_{\mathrm{h}}^{\mathrm{c}}\left(1-v_{\mathrm{hz}}^{\mathrm{c}^{2}}\right)}{E_{\mathrm{h}}^{\mathrm{c}}\left(1-v^{\mathrm{r}^{\mathrm{r}}}\right)} .
$$


Substituting the combination of Eqs. (5), (6) and (13) into Eq. (14), we get

$$
\delta \sigma_{\mathrm{h}}^{\mathrm{s}}=\frac{E^{\mathrm{s}} \delta \sigma_{\mathrm{h}}^{\mathrm{r}}\left(1-v^{\mathrm{r}^{2}}\right)}{E^{\mathrm{r}}\left(1-v^{\mathrm{s}^{\mathrm{s}}}\right)} .
$$

From Eqs. (16) and (17), $E_{\mathrm{h}}^{\mathrm{c}}$ can be written as

$$
E_{\mathrm{h}}^{\mathrm{c}}=\frac{E^{\mathrm{r}} \delta \sigma_{\mathrm{h}}^{\mathrm{c}}\left(1-v_{\mathrm{hz}}^{\mathrm{c}^{2}}\right)}{\delta \sigma_{\mathrm{h}}^{\mathrm{r}}\left(1-v^{\mathrm{r}^{\mathrm{r}}}\right)}
$$

The horizontal tangent modulus, $E_{\mathrm{h}}^{\mathrm{c}}$, can be rewritten as follows according to Eqs. (3), (17) and (18):

$$
E_{\mathrm{h}}^{\mathrm{c}}=\frac{\left(1-v_{\mathrm{hz}}^{\mathrm{c}^{2}}\right)}{(1+\eta)}\left[\frac{\eta E^{\mathrm{r}}}{1-v^{\mathrm{r}^{2}}}+\frac{E^{\mathrm{s}}}{1-v^{\mathrm{s}^{\mathrm{s}}}}\right]
$$

Since the anti-plane Poisson's ratio, $v_{\mathrm{hz}}^{\mathrm{c}}$, can be expressed as

$$
v_{\mathrm{hz}}^{\mathrm{c}}=\frac{\eta v^{\mathrm{r}} E^{\mathrm{r}} /\left(1-v^{\mathrm{r}^{2}}\right)+v^{\mathrm{s}} E^{\mathrm{s}} /\left(1-v^{\mathrm{s}^{2}}\right)}{\eta E^{\mathrm{r}} /\left(1-v^{\mathrm{r}^{2}}\right)+E^{\mathrm{s}} /\left(1-v^{\mathrm{s}^{2}}\right)},
$$

which will be derived later, it follows that $E_{\mathrm{h}}^{\mathrm{c}}$ can be represented as

$$
E_{\mathrm{h}}^{\mathrm{c}}=\frac{1}{1+\eta}\left[\frac{\left(\Omega^{\mathrm{r}}+\Omega^{\mathrm{s}}\right)^{2}-\left(v^{\mathrm{r}} \Omega^{\mathrm{r}}+v^{\mathrm{s}} \Omega^{\mathrm{s}}\right)^{2}}{\left(\Omega^{\mathrm{r}}+\Omega^{\mathrm{s}}\right)}\right],
$$

in which

$$
\Omega^{\mathrm{r}}=\frac{\eta E^{\mathrm{r}}}{1-v^{\mathrm{r}}} ; \quad \Omega^{\mathrm{s}}=\frac{E^{\mathrm{s}}}{1-v^{\mathrm{s}^{2}}} .
$$

\subsection{Anti-plane Poisson's ratio, $v_{\mathrm{hz}}^{\mathrm{c}}$}

$v_{\mathrm{hz}}^{\mathrm{c}}$ is the Poission's ratio of the transverse strain due to the horizontal stress on the reinforced soil, $\delta \sigma_{\mathrm{h}}^{\mathrm{c}}$. Considering the plane strain case only, we have

$$
\begin{aligned}
& \delta \sigma_{\mathrm{z}}^{\mathrm{c}}=v_{\mathrm{hz}}^{\mathrm{c}} \delta \sigma_{\mathrm{h}}^{\mathrm{c}}, \\
& \delta \sigma_{\mathrm{z}}^{\mathrm{r}}=v^{\mathrm{r}} \delta \sigma_{\mathrm{h}}^{\mathrm{r}}
\end{aligned}
$$

and

$$
\delta \sigma_{\mathrm{z}}^{\mathrm{s}}=v^{\mathrm{s}} \delta \sigma_{\mathrm{h}}^{\mathrm{s}} .
$$

As explained earlier, the stress distribution in the $\mathrm{z}$ direction can be expressed as

$$
\delta \sigma_{\mathrm{z}}^{\mathrm{c}}=\frac{\eta}{1+\eta} \delta \sigma_{\mathrm{z}}^{\mathrm{r}}+\frac{1}{1+\eta} \delta \sigma_{\mathrm{z}}^{\mathrm{s}}
$$

Substituting Eqs. (23) and (24) into Eq. (25), we have

$$
\delta \sigma_{\mathrm{z}}^{\mathrm{c}}=\frac{\eta}{1+\eta} v^{\mathrm{r}} \delta \sigma_{\mathrm{h}}^{\mathrm{r}}+\frac{1}{1+\eta} v^{\mathrm{s}} \delta \sigma_{\mathrm{h}}^{\mathrm{s}} .
$$


Again, substituting Eqs. (15) and (16) into Eq. (28), we have

$$
\delta \sigma_{\mathrm{z}}^{\mathrm{c}}=v_{\mathrm{hz}}^{\mathrm{c}} \delta \sigma_{\mathrm{h}}^{\mathrm{c}}=\left(\frac{\eta}{1+\eta}\right) \frac{v^{\mathrm{r}} \delta \sigma_{\mathrm{h}}^{\mathrm{c}} E^{\mathrm{r}}\left(1-v_{\mathrm{h}}^{\mathrm{c}^{2}}\right)}{E_{\mathrm{h}}^{\mathrm{c}}\left(1-v_{\mathrm{r}}^{\mathrm{c}^{2}}\right)}+\left(\frac{1}{1+\eta}\right) \frac{v^{\mathrm{s}} \delta \sigma_{\mathrm{h}}^{\mathrm{c}} E^{\mathrm{s}}\left(1-v_{\mathrm{h}}^{\mathrm{c}^{2}}\right)}{E_{\mathrm{h}}^{\mathrm{c}}\left(1-v^{\mathrm{s}^{2}}\right)} .
$$

Substituting $E_{\mathrm{h}}^{\mathrm{c}}$ in Eq. (21) into Eq. (27), we can express the anti-plane Poisson's ratio as

$$
v_{\mathrm{hz}}^{\mathrm{c}}=\frac{v^{\mathrm{r}} \Omega^{\mathrm{r}}+v^{\mathrm{s}} \Omega^{\mathrm{s}}}{\Omega^{\mathrm{r}}+\Omega^{\mathrm{s}}}
$$

\subsection{In-plane Poisson's ratio, $v_{\mathrm{hv}}^{\mathrm{c}}$}

$v_{\mathrm{hv}}^{\mathrm{c}}$ is the Poisson's ratio of the vertical strain due to the horizontal stress on the reinforced soil, $\delta \sigma_{\mathrm{h}}$. The vertical strain increment of the reinforced soil is expressed in Eq. (9):

$$
\delta \varepsilon_{\mathrm{v}}^{\mathrm{c}}=-\frac{\nu_{\mathrm{hv}}^{\mathrm{c}}}{E_{\mathrm{h}}^{\mathrm{c}}} \delta \sigma_{\mathrm{h}}^{\mathrm{c}}+\frac{\delta \sigma_{\mathrm{v}}^{\mathrm{c}}}{E_{\mathrm{v}}^{\mathrm{c}}}-\frac{\nu_{\mathrm{hv}}^{\mathrm{c}}}{E_{\mathrm{h}}^{\mathrm{c}}} \delta \sigma_{\mathrm{z}}^{\mathrm{c}}
$$

Similarly, the vertical strain increment of the reinforcement and the soil, respectively, can be expressed as

$$
\delta \varepsilon_{\mathrm{v}}^{\mathrm{r}}=-\frac{v^{\mathrm{r}}}{E^{\mathrm{r}}} \delta \sigma_{\mathrm{h}}^{\mathrm{r}}+\frac{\delta \sigma_{\mathrm{v}}^{\mathrm{r}}}{E^{\mathrm{r}}}-\frac{v^{\mathrm{r}}}{E^{\mathrm{r}}} \delta \sigma_{\mathrm{z}}^{\mathrm{r}}
$$

and

$$
\delta \varepsilon_{\mathrm{v}}^{\mathrm{s}}=-\frac{v^{\mathrm{s}}}{E^{\mathrm{s}}} \delta \sigma_{\mathrm{h}}^{\mathrm{s}}+\frac{\delta \sigma_{\mathrm{v}}^{\mathrm{s}}}{E^{\mathrm{s}}}-\frac{v^{\mathrm{s}}}{E^{\mathrm{s}}} \delta \sigma_{\mathrm{z}}^{\mathrm{s}} .
$$

Based on the earlier explanation of the stress state, Eq. (29) can be rewritten as

$$
\begin{aligned}
\delta \varepsilon_{\mathrm{v}}^{\mathrm{c}} & =-\frac{v_{\mathrm{hv}}^{\mathrm{c}}}{E_{\mathrm{h}}^{\mathrm{c}}}\left(\delta \sigma_{\mathrm{h}}^{\mathrm{c}}+\delta \sigma_{\mathrm{z}}^{\mathrm{c}}\right) \\
& =-\frac{\eta v^{\mathrm{r}}}{(1+\eta) E^{\mathrm{r}}}\left(\delta \sigma_{\mathrm{h}}^{\mathrm{r}}+\delta \sigma_{\mathrm{z}}^{\mathrm{r}}\right)-\frac{v^{\mathrm{s}}}{(1+\eta) E^{\mathrm{s}}}\left(\delta \sigma_{\mathrm{h}}^{\mathrm{s}}+\delta \sigma_{\mathrm{z}}^{\mathrm{s}}\right) .
\end{aligned}
$$

Considering the plane strain case, we have

$$
\begin{aligned}
& \delta \sigma_{\mathrm{z}}^{\mathrm{c}}=v_{\mathrm{hz}}^{\mathrm{c}} \delta \sigma_{\mathrm{h}}^{\mathrm{c}}, \\
& \delta \sigma_{\mathrm{z}}^{\mathrm{r}}=v^{\mathrm{r}} \delta \sigma_{\mathrm{h}}^{\mathrm{r}}
\end{aligned}
$$

and

$$
\delta \sigma_{\mathrm{z}}^{\mathrm{s}}=v^{\mathrm{s}} \delta \sigma_{\mathrm{h}}^{\mathrm{s}} .
$$


We can substitute Eqs. (16) and (33) into Eq. (32) to get the in-plane Poisson's ratio as

$$
v_{\mathrm{hv}}^{\mathrm{c}}=\frac{\left(1-v^{\mathrm{r}}\right) \Omega^{\mathrm{r}}+\left(1-v^{\mathrm{s}}\right) \Omega^{\mathrm{s}}}{(1+\eta)\left(\Omega^{\mathrm{r}}+\Omega^{\mathrm{s}}\right)}\left(\Psi^{\mathrm{r}}+\Psi^{\mathrm{s}}\right)
$$

in which $\Psi^{\mathrm{r}}=\eta v^{\mathrm{r}} /\left(1-v^{\mathrm{r}}\right)$ and $\Psi^{\mathrm{s}}=v^{\mathrm{s}} /\left(1-v^{\mathrm{s}}\right)$.

\subsection{Elastic modulus in the vertical direction and shear modulus}

Following similar procedures, the elastic modulus in the vertical direction and the shear modulus can be expressed, respectively, as

$$
\frac{1}{E_{\mathrm{v}}^{\mathrm{c}}}=\frac{1}{1+\eta}\left\{\left(\frac{\eta^{2}}{\Omega^{\mathrm{r}}}+\frac{1}{\Omega^{\mathrm{s}}}\right)+\left[\frac{-1}{\Omega^{\mathrm{r}}+\Omega^{\mathrm{s}}}+\frac{2}{\left(1+v^{\mathrm{r}}\right) \Omega^{\mathrm{r}}+\left(1+v^{\mathrm{s}}\right) \Omega^{\mathrm{s}}}\right]\left(\Psi^{\mathrm{r}}+\Psi^{\mathrm{s}}\right)^{2}\right\}
$$

and

$$
\frac{1}{G_{\mathrm{hv}}^{\mathrm{c}}}=\frac{1}{1+\eta}\left(\frac{\eta^{2}}{\Omega^{\mathrm{r}}}+\frac{1}{\Omega^{\mathrm{s}}}\right)+\frac{1+2 v_{\mathrm{hv}}^{\mathrm{c}}+v_{\mathrm{hv}}^{\mathrm{c}^{2}}}{E_{\mathrm{h}}^{\mathrm{c}}}=\frac{1}{1+\eta}\left(\frac{\eta^{2}}{\Omega^{\mathrm{r}}}+\frac{1}{\Omega^{\mathrm{s}}}\right)+\frac{\left(1+v_{\mathrm{hv}}^{\mathrm{c}}\right.}{E^{2}} E_{\mathrm{h}}^{\mathrm{c}} .
$$

Detailed derivations for Eqs. (35) and (36) can be found in Chen (1998).

\section{Materials modeling}

\subsection{Tangent modulus of the elasticity of the soil}

Since the soil stiffness increases along with both of the increase of the confining pressure and the strain magnitude, the hyperbolic soil modulus, proposed by Duncan and Chang (1970), can be used to simulate the nonlinear stress - strain behavior of the soil and is expressed as

$$
E^{\mathrm{s}}=E^{\mathrm{si}}\left(1-\frac{E^{\mathrm{si}} \varepsilon}{\left(\sigma_{1}-\sigma_{3}\right)_{\mathrm{ult}}+E^{\mathrm{si}} \varepsilon}\right),
$$

in which $E^{\mathrm{s}}$ is the tangent modulus of the soil; $\varepsilon$ is the strain magnitude; $\left(\sigma_{1}-\sigma_{3}\right)_{\text {ult }}$ is the ultimate deviatoric stress of the soil; and $E^{\text {si }}$ is the initial tangent modulus, which was proposed by Janbu (1963) and is expressed as

$$
E^{\mathrm{si}}=k_{\mathrm{s}} P_{\mathrm{a}}\left(\frac{\sigma_{\mathrm{m}}}{P_{\mathrm{a}}}\right)^{\mathrm{ns}} \text {. }
$$

in which $k_{\mathrm{s}}$, ns are material constants; $\sigma_{\mathrm{m}}$ is mean stress; $P_{\mathrm{a}}$ is atmospheric pressure. 


\subsection{Reinforcement behavior}

The reinforcement is considered to be a linear elastic material in this study although a more complex model, such as a hyperbolic or a three-parameter relation, can also be used.

\section{Numerical procedures}

The commercial computer code FLAC (1993) was used in the numerical analysis. By applying the FISH function to the code FLAC, the proposed model of the reinforced soil could be included in the analysis. In addition, the iteration procedure was used for analysis of the nonlinear behaviors of the soil. The detailed numerical procedures can be found in Chen (1998).

\section{Comparisons of numerical and experimental test results}

Results obtained using the proposed method have been compared with experimental data obtained by Wu (1991) using an in-door test wall at the University of Colorado and by the Texas State Department of Highways and Public Transportation (TSDHPT) in 1991 using a full-scale test wall (Sampaco, 1996).

\subsection{University of colorado wall}

A reinforced soil wall (Fig. 2), $3.05 \mathrm{~m}$ high $2.08 \mathrm{~m}$ wide and reinforced with 12 layers of nonwoven geotextile, was built at the University of Colorado by Wu (1991). Wood planks were used for facing panels. The reinforcement is $1.68 \mathrm{~m}$ long, except for the top and the bottom layers, which are $1.98 \mathrm{~m}$ long. In addition, the vertical spacing between the reinforcement layers is $27.9 \mathrm{~cm}$, except for the bottom layer, which is $17.8 \mathrm{~cm}$ above the base. The material properties of the wood planks and the reinforcement are listed in Table 1. In addition, the tested wall was backfilled with Ottawa sand, whose properties are listed in Table 2.

The effective equivalent material moduli were calculated via Eqs. (21), (28), (34)-(36), in which the nonlinear properties of the soil in Eqs. (37) and (38) were used. The soil samples taken from the middle and bottom portions of the testing wall were tested by $\mathrm{Wu}$ (1991) and have the properties shown in Figs. 3-5, which show that the equivalent material moduli of the reinforced soil are highly nonlinear. In the analysis, these equivalent material moduli were updated after each iteration procedure.

The mesh used and the boundary conditions considered for the numerical analyses are shown in Fig. 6. Beam elements were used to simulate the facing panels. A roller and hinge were used at rear and bottom, respectively, of the testing wall to simulate the boundary conditions. In addition, three different surcharges, 103, 186 and 200 $\mathrm{kPa}$, were considered in the analyses. 


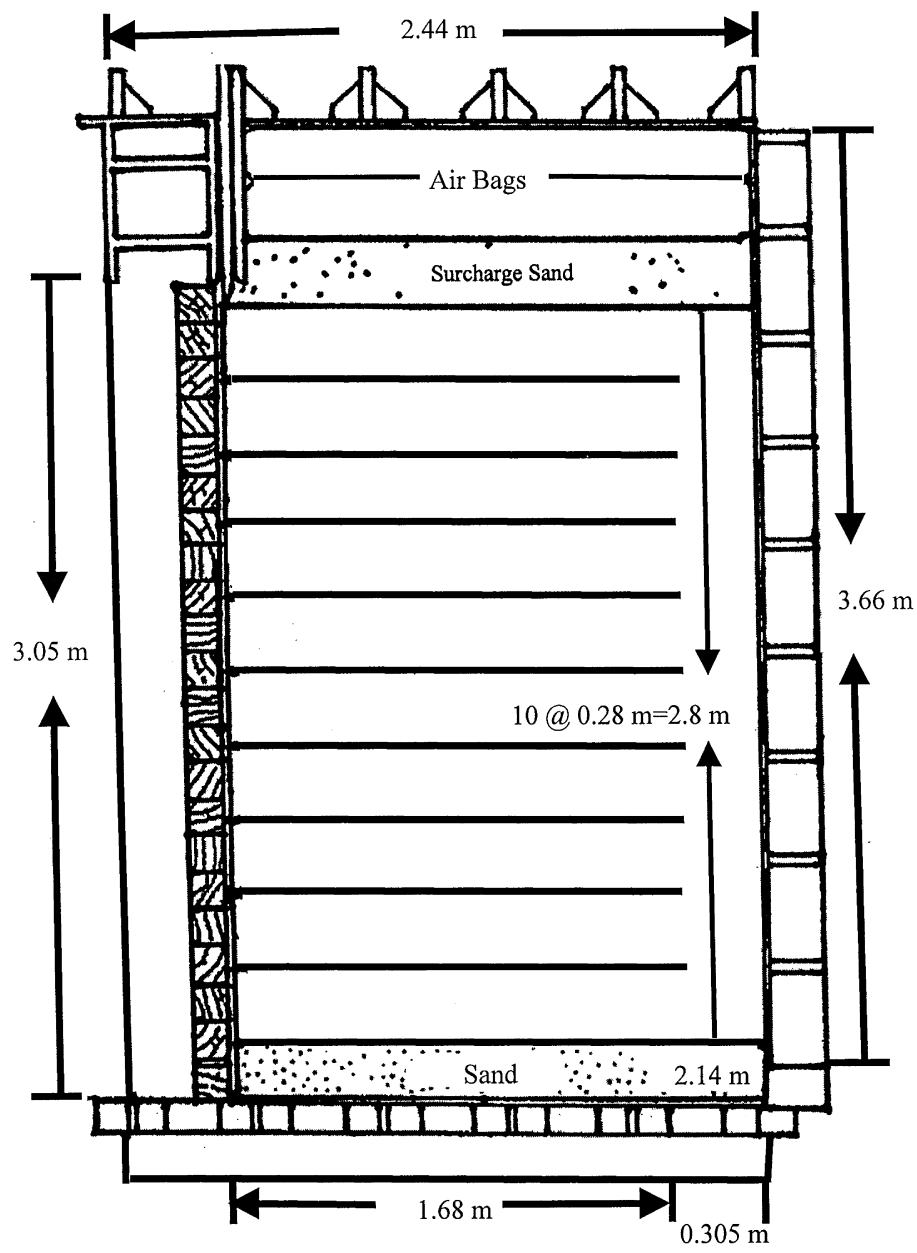

Fig. 2. University of Colorado Wall (Wu, 1991).

Table 1

Geotextile and facing panel properties of the University of Colorado Wall (Wu, 1991)

\begin{tabular}{llc}
\hline Material & Parameter & Value \\
\hline Geotextile & Elastic modulus, $E^{\mathrm{r}}(\mathrm{MPa})$ & 31.35 \\
& Poisson's ratio, $v^{\mathrm{r}}$ & 0.28 \\
& Ratio of reinforcement volume, $\eta$ & $2.87 \times 10^{-2}$ \\
& Cross-sectional area, $A\left(\mathrm{~m}^{2} / \mathrm{m}\right)$ & $2.79 \times 10^{-4}$ \\
Facing panel & Elastic modulus, $E(\mathrm{MPa})$ & 26.1 \\
& Moment of inertia, $I\left(\mathrm{~m}^{4} / \mathrm{m}\right)$ & 0.121 \\
& Cross-sectional area, $A\left(\mathrm{~m}^{2} / \mathrm{m}\right)$ & 0.11 \\
\hline
\end{tabular}


Table 2

Soil properties of the University of Colorado Wall (Wu, 1991)

\begin{tabular}{lc}
\hline Backfill soil property & Value \\
\hline Unit weight, $\gamma\left(\mathrm{kN} / \mathrm{m}^{3}\right)$ & 17.14 \\
Frictional angle, $\phi($ degree $)$ & 38 \\
Poisson's ratio, $v^{\mathrm{s}}$ & 0.3 \\
$k_{\mathrm{s}}$ & 1355 \\
$\mathrm{~ns}$ & 0.66 \\
\hline
\end{tabular}

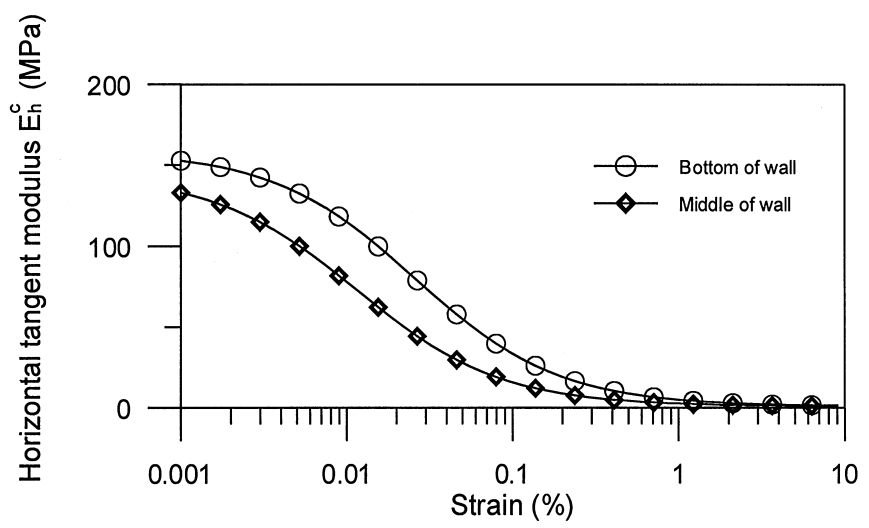

Fig. 3. Horizontal tangent modulus $E_{\mathrm{h}}^{\mathrm{c}}$ used in the Colorado wall analysis ( $\left.\mathrm{Wu}, 1991\right)$.

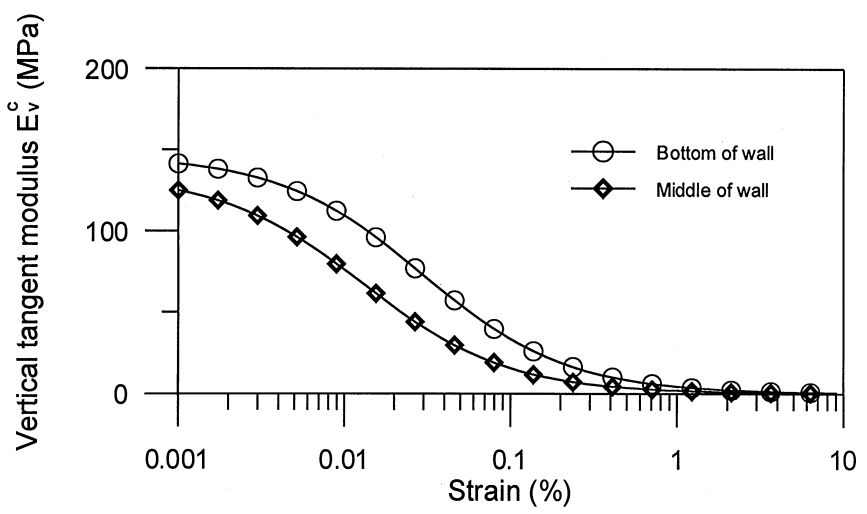

Fig. 4. Vertical tangent modulus $E_{\mathrm{v}}^{\mathrm{c}}$ used in the Colorado wall analysis (Wu, 1991).

The predicted and the measured vertical displacements at the top of the wall, under different vertical external pressures, are shown in Fig. 7. The fact that the roller boundary conditions at the back of the wall were assumed in the numerical analysis may be the reason why the predicted displacements at the back of the wall are slightly 


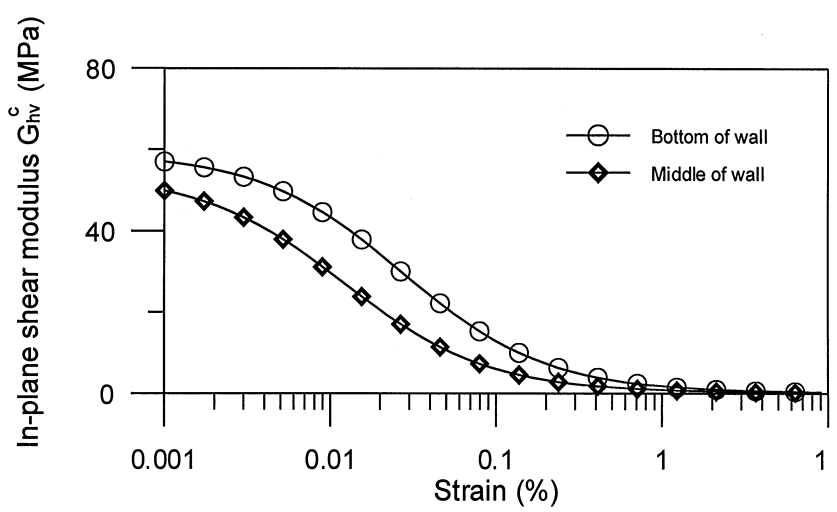

Fig. 5. In-plane shear modulus $G_{\mathrm{hv}}^{\mathrm{c}}$ used in the Colorado wall analysis (Wu, 1991).

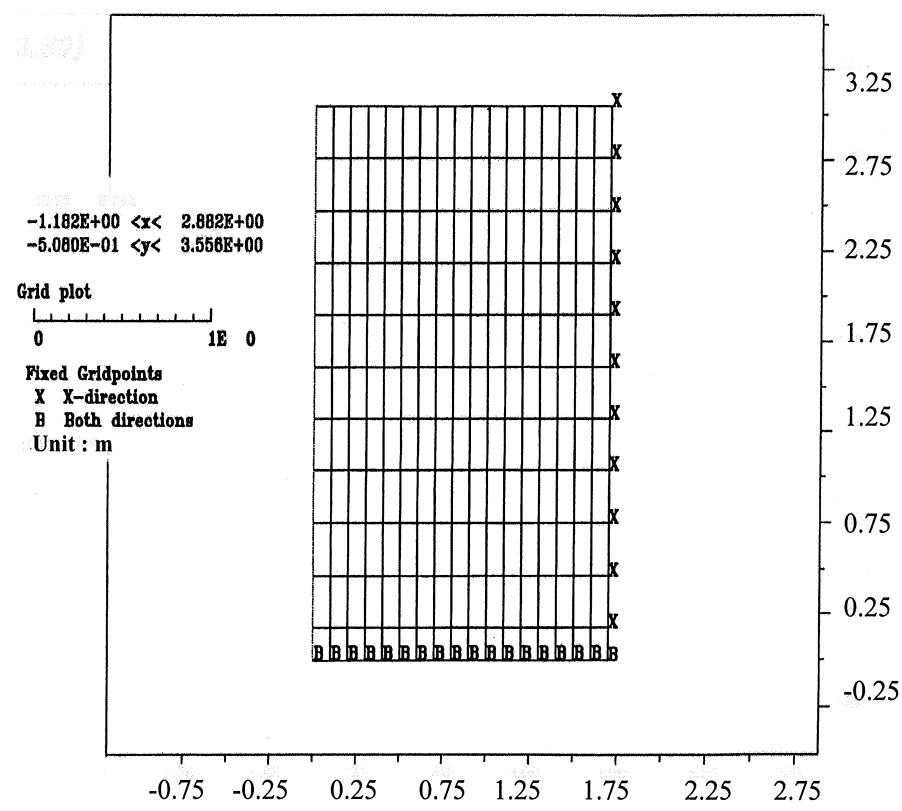

Fig. 6. Meshes and boundary conditions of Colorado Wall.

higher than the measured results. In general, the measured and the calculated results show good agreement. The horizontal displacement at the face of the wall is also shown in Fig. 8. In addition, when the wall was tested under a pressure of $200 \mathrm{kPa}$, it failed due to excessive displacements; this level of pressure is beyond the prediction capacity of the proposed method. 


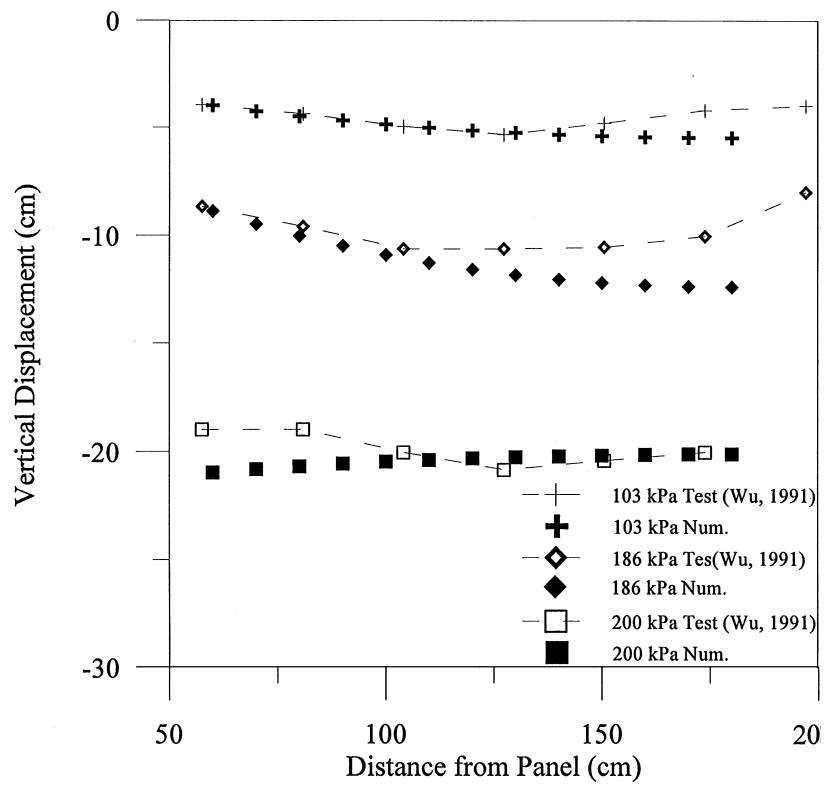

Fig. 7. Measured vs. numerical results of vertical displacement at the top of the facing panel.

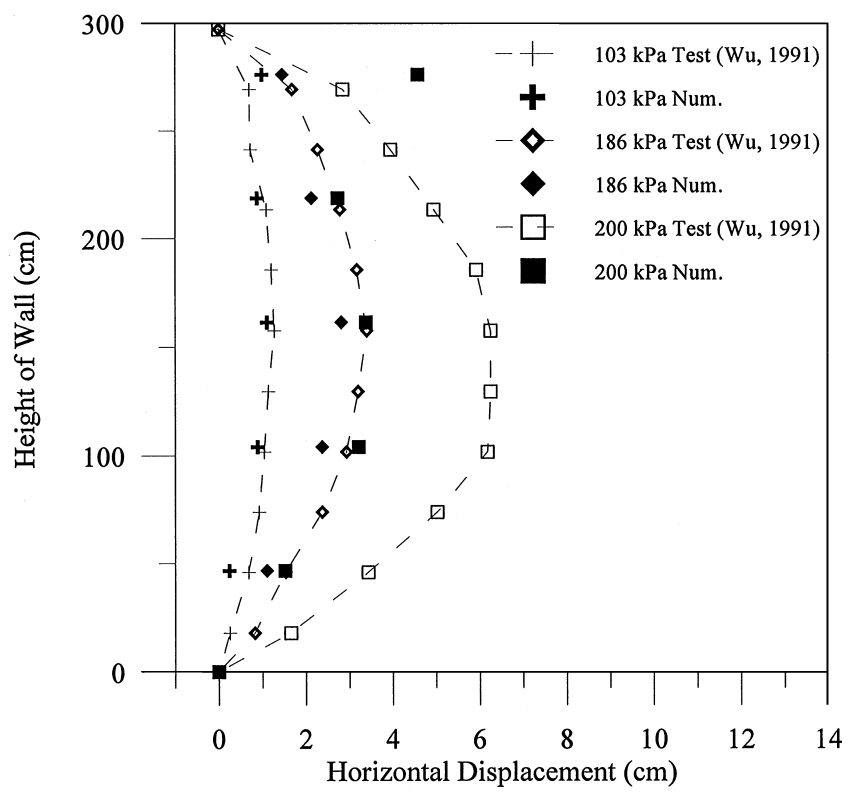

Fig. 8. Measured vs. numerical results of horizontal displacement of the facing panel. 


\subsection{TSDHPT wall}

In 1991, the TSDHPT initiated a highway expansion program for the city of Houston, which involved the construction of nine double-faced welded wire mesh reinforced soil walls along state highway 225. An instrumentation program was carried out on one of the walls. The instrumented section of wall 17 (Fig. 9) consists of 14 reinforcement and panel layers. A typical layer consists of two $1.2 \mathrm{~m}$ wide by $3.6 \mathrm{~m}$ long reinforcing mats, connected to a $0.75 \mathrm{~m}$ high $3.75 \mathrm{~m}$ long $21.7 \mathrm{~cm}$ thick segmented smooth-faced concrete facing panel. The detailed reinforcement and face panel properties of the wall and the soil properties are listed in Tables 3 and 4

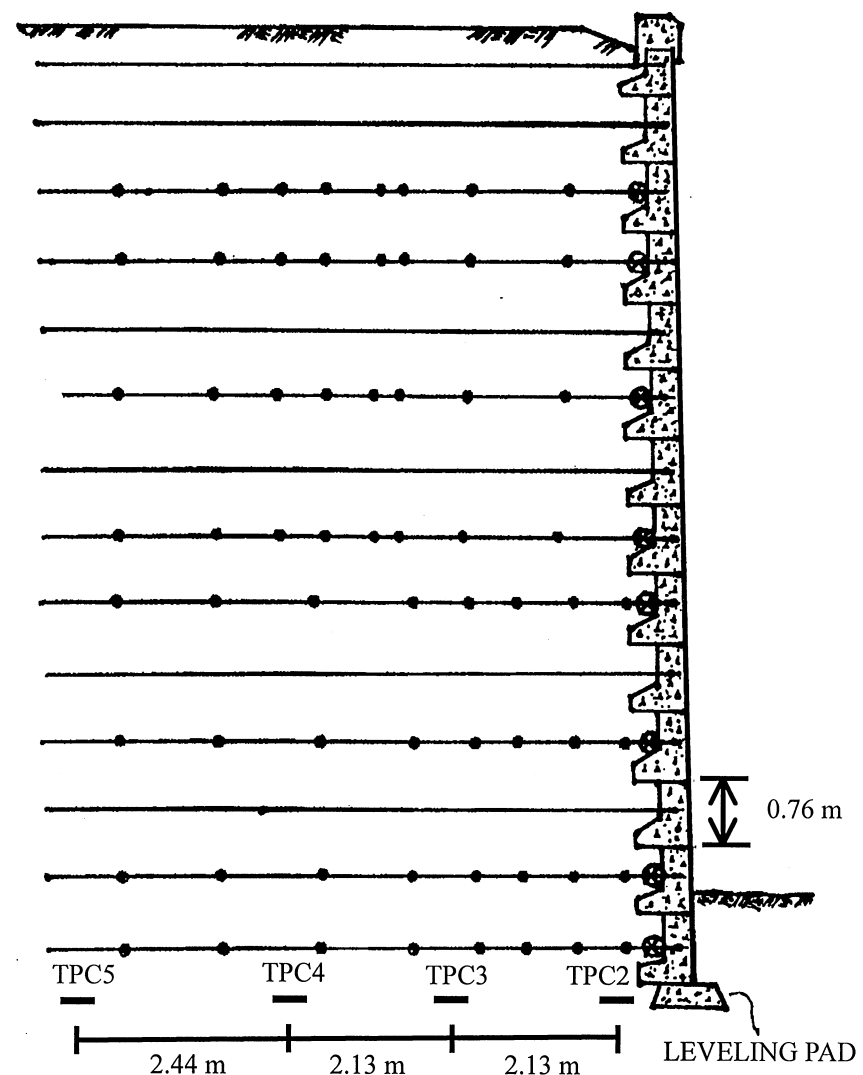

LEGEND :

- MAT GAGES

\& ANCHOR GAGES

- TOTAL PRESSURE CELLS (TPC)

Fig. 9. TSDHPT Wall 17 (Sampaco, 1996). 
Table 3

Material properties of the welded wire mesh and facing panel of the TSDHPT wall (Sampaco, 1996)

\begin{tabular}{lll}
\hline Material & Parameter & Value \\
\hline Welded wire mesh & Elastic modulus, $E^{\mathrm{r}}(\mathrm{MPa})$ & $2.0 \times 10^{-5}$ \\
& Poisson's ratio, $v^{\mathrm{r}}$ & 0.25 \\
& Cross-sectional area, $A\left(\mathrm{~m}^{2} / \mathrm{m}\right)$ & $4.27 \times 10^{-4}$ \\
& (a) layer 1-5 & $3.66 \times 10^{-4}$ \\
& (b) layer 6-7 & $2.9 \times 10^{-4}$ \\
(c) layer 8-9 & $2.13 \times 10^{-4}$ \\
& (d) layer 10-11 & $1.37 \times 10^{-4}$ \\
& (e) layer 12-13 & $6.897 \times 10^{3}$ \\
Facing panel & Elastic modulus, $E(\mathrm{MPa})$ & $1.71 \times 10^{-4}$ \\
& Moment of inertia, $I\left(\mathrm{~m}^{4} / \mathrm{m}\right)$ & 0.128 \\
\hline
\end{tabular}

Table 4

Soil properties of the TSDHPT Wall (Sampaco, 1996)

\begin{tabular}{lcc}
\hline Soil parameter & Backfill soil & Foundation soil \\
\hline Unit weight, $\gamma\left(\mathrm{kN} / \mathrm{m}^{3}\right)$ & 19.6 & 20.8 \\
Frictional angle, $\phi($ degree $)$ & 38 & 38 \\
Passion's ratio, $v^{\mathrm{s}}$ & 0.3 & 0.3 \\
$k_{\mathrm{s}}$ & 140 & 600 \\
$\mathrm{~ns}$ & 0.3 & 0.25 \\
\hline
\end{tabular}

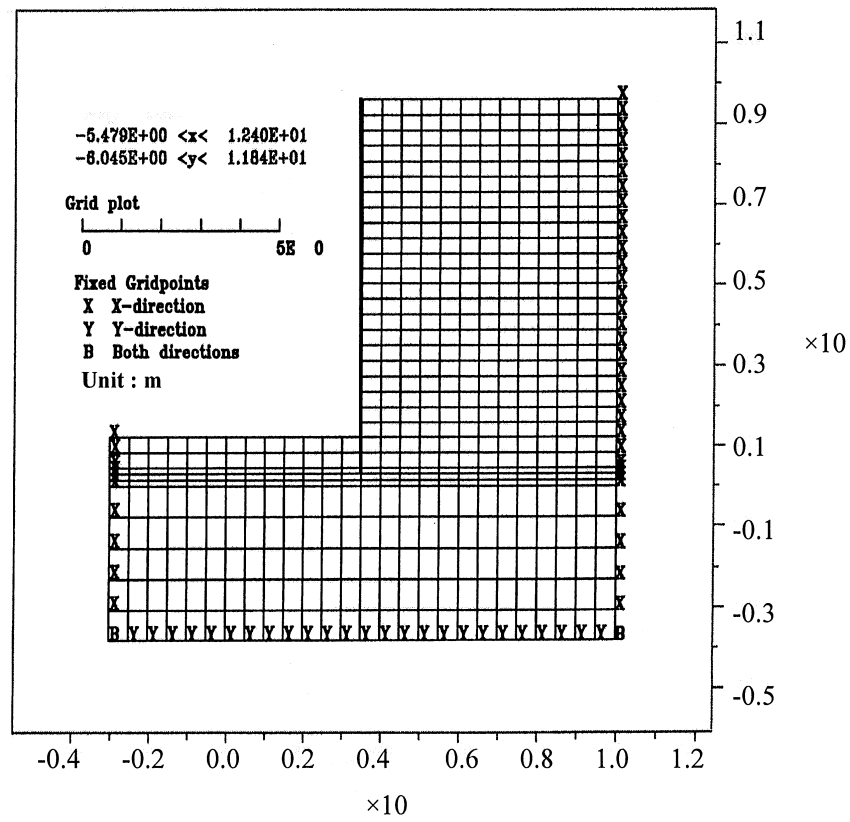

Fig. 10. Meshes and boundary conditions of the TSDHPT wall. 


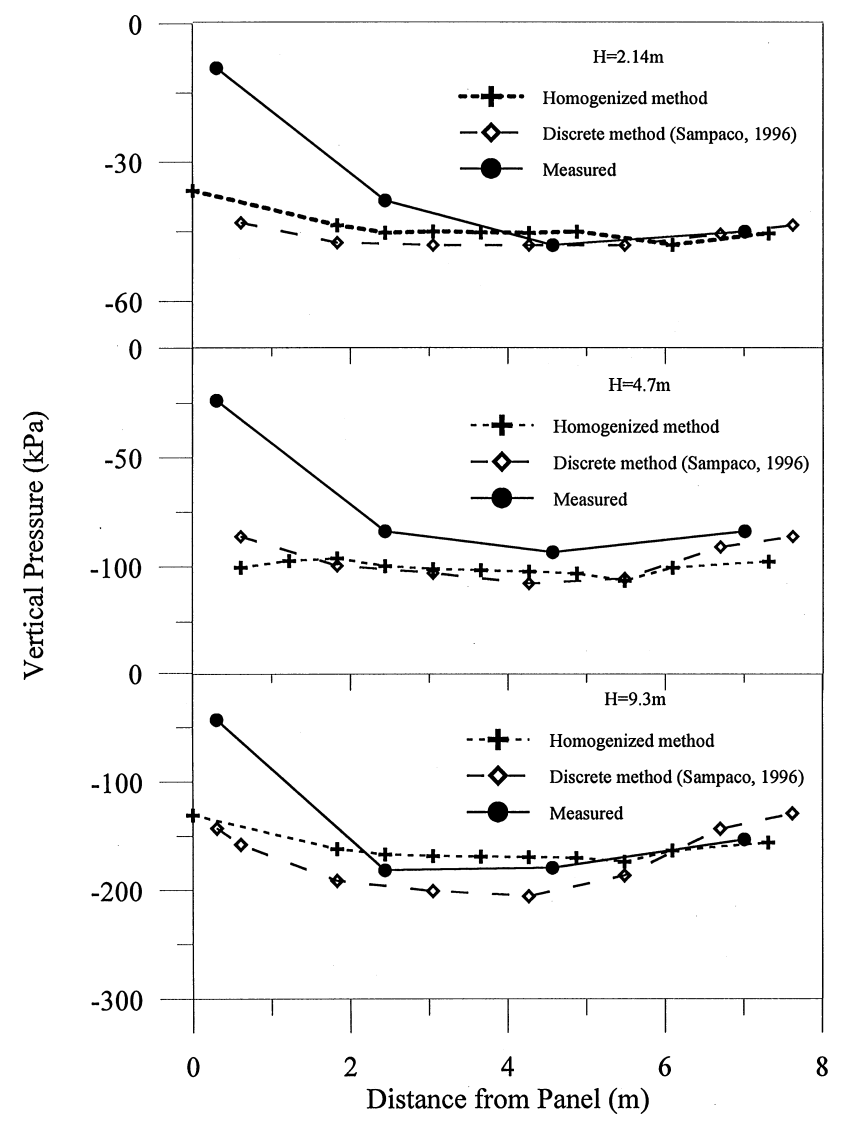

Fig. 11. Measured vs. numerical results of vertical pressure at the bottom of the TSDHPT wall.

respectively. In addition, the mesh and the boundary conditions for numerical studies of the considered structure are shown in Fig. 10.

The measured and the calculated vertical pressures at the base of the tested wall at three different construction levels are shown in Fig. 11. In addition, the predicted results obtained by Sampaco (1996) using the discrete method are also shown in Fig. 11 for comparison. A detailed description of the discrete method has been given by Sampaco (1996). Both predicted results show good agreement with the measured results, except for the values at the measured points closest to the face of the wall. However, the vertical base pressure obtained using the discrete and that obtained using the proposed homogenized methods show very close distribution trends. Fig. 12 shows the predicted horizontal displacements at facing panels along the wall. This result shows that most of the displacement occurred in the bottom one-third of the wall. 


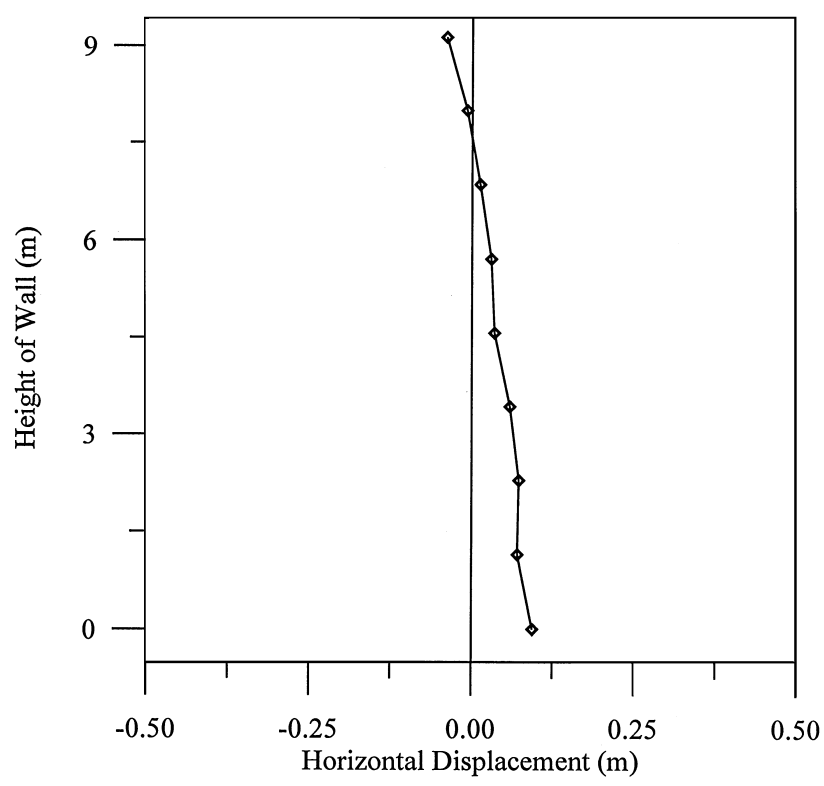

Fig. 12. Predicted horizontal displacement of the TSDHPT wall.

\section{Summary and conclusions}

A homogenized, transversely isotropic concept has been used to simulate reinforced soil. The model used to represent the reinforced soil properties is capable of simulating the nonlinear behaviors of reinforced soils. A commercially available finite difference program (FLAC) has been used which allows potential users to implement the proposed concept easily. Comparison of the predicted results with available test data shows reasonable agreement. However, ignoring the interface behavior, some aspects, such as reinforced steep slopes, may not be investigated using the present homogenized approach. A reinforced steep slope derives its stability from the tensile force of the reinforcement made possible by interaction at the front and rear end of the reinforcement. However, the method is still relevant when an additional failure condition relative to the interface between the soil and the reinforcement is taken into account.

\section{Acknowledgement}

The writers are thankful to the reviewers for their valuable suggestions and comments.

\section{References}

Anthoine, A., 1989. Mixed modeling of reinforced soils within the framework of the yield design theory. Computers and Geotechnics 7, 67-82. 
Buhan, P., Mangiavacchi, R., Nova, R., Pellegrini, G., Salencon, J., 1989. Yield design of reinforced earth walls by a homogenization method. Géotechnique 39, 189-201.

Chen, R.H., Chen, T.C., Lin, S.S., 1999. A homogenized transversely isotropic model for cyclic behaviors of reinforced soil, Journal of Chinese Institute of Engineers 22, in press.

Chen, T.C., 1998. Static and dynamic analyses of reinforced soil walls using a homogenized concept (in Chinese). Ph.D. Thesis. National Taiwan University, Taipei, Taiwan.

Chen, T.C., Chen, R.H., 1997. The anisotropic method for reinforced retaining wall analysis (in Chinese). Proceedings of the seventh Conference on Current Researches in Geotechnical Engineering in Taiwan, Taipei, Taiwan, 751-758.

Duncan, J.M., Chang, C.Y., 1970. Nonlinear analysis of stress and strain in soils. Journal of Soil Mechanics \& Foundations, ASCE 96, 1629-1653.

FLAC program, 1993. Itasca Consulting Groups, Inc., USA.

Gerrard, C., 1982. Reinforced soil: an orthorhombic material. Journal of Geotechnical Engineering ASCE $108,1460-1474$.

Harrison, W.J., Gerrard, C., 1972. Elastic theory applied to reinforced earth. Journal of Soil Mechanics and Foundations, ASCE 98, 1325-1345.

Janbu, N., 1963. Soil compressibility as determined by oedometer and triaxial test. Proceedings of the European Conference on Soil Mechanics and Foundation Engineering, Wiesbaden, Germany, Vol. 1, pp. 19-25.

Lee, W.F., Holtz, R.D., 1998. Analysis of geosynthetic reinforced soil retaining walls using composite material properties. Proceedings of the 13th Southeast Asian Geotechnical Conference, Taipei, Taiwan, pp. 349-354.

Michalowski, R.L., Zhao, A., 1995. Continuum versus structural approach to stability of reinforced soil. Journal of Geotechnical Engineering ASCE 121, 152-162.

Moroto, N., Hasegawa, A., 1990. Anisotropic elastic stress formulae applicable to reinforced earth. Soils and Foundations, JSCE 30, 172-178.

Romstad, K.M., Herrmann, L.R., Shen, C.K., 1976. Integrated study of reinforced earth- I: theoretical formulation. Journal Geotechnical Engineering ASCE 102, 457-471.

Sampaco, C.L., 1996. Behavior of welded wire mesh reinforced soil walls from field evaluation and finite element simulation. Ph.D. Thesis. Utah State University, Logan, Utah.

Wu, T.H., 1991. Predicting performance of the Denver walls: general report. Proceedings of the International Symposium on Geosynthetic-reinforced Soil Retaining Walls, Denver, Colorado, USA, pp. 3-20. 